\title{
The Influence of Aluminum on the Flocculation of Activated Sludge with Different Concentrations
}

\author{
Hang Zhang ${ }^{1, a}$, Yue Wen ${ }^{1, b}$ \\ ${ }^{1}$ State Key Laboratory of Pollution Control and Resource Reuse, College of Environmental Science \\ and Engineering, Tongji University, Shanghai 200092, PR China. \\ azhang_juily@163.com, ${ }^{b}$ weny@tongji.edu.cn
}

\begin{abstract}
Keywords: Aluminum ion, Flocculation, Activated sludge, Extracellular polymeric substances
Abstract. The mechanism governing the flocculation of activated sludge (AS) with different concentrations of aluminum was studied in this paper. The AS samples were cultivated in sequencing batch reactors at $22{ }^{\circ} \mathrm{C}$. The sludge retention times (SRT) was $15 \mathrm{~d}$. The dosages of $\mathrm{Al}^{3+}$ were 0.00 , $0.0625,0.125,0.250,0.500,1.00,2.00$ and $4.00 \mathrm{meq} / \mathrm{L}$. The experimental results indicated that the dosage of $\mathrm{Al}^{3+}$ could enhance sludge flocculation, but deteriorate sedimentation. It was also found that as $\mathrm{Al}^{3+}$ dosage $(\leq 2 \mathrm{meq} / \mathrm{L})$ increased, the total interaction energy, and loosely bound extracellular polymeric substances (LB-EPS) content decreased, indicating that the dosage of $\mathrm{Al}^{3+}$ could enhance sludge flocculation.
\end{abstract}

\section{Introduction}

Activated sludge (AS) systems are the most widely used biological wastewater treatment process. The quality of effluent has a close relation to the efficient solideliquid separation. $\mathrm{Al}^{3+}$ is the most common flocculant in wastewater treatment. The flocculation of activated sludge is affected by physical, chemistry and biological factors [1]. All theories about intermolecular force can be used to explain the binding of AS entities such as polymer bridging, Derjaguin-Landau-Verwey-Overbeek (DLVO) theory, hydrophobic interactions, multivalent bridging theory, and steric interactions $[2,3,4]$.

The DLVO theory, named after its developers, Derjaguin, Landau, Verwey, and Overbeek, is a classical colloidal theory that describes charged particles as having a double layer of counterions surrounding the particle. It is often used to interpret colloid stability and to describe the microorganisms and AS flocculation [3]. EPS, which accounts for about $80 \%$ of the dry weight of AS, mainly consists of polysaccharide, protein, nucleic acid and humic compounds [4]. It plays an important role in the ion bridging theory. Researchers found that the interior layer of the EPS was tightly bound EPS (TB-EPS), which had a certain shape and stuck to the cellular surface closely and stably, whereas the exterior layer of the EPS was loosely bound EPS (LB-EPS), which was a loose and dispersible slime layer and had no clear boundaries [5]. EPS also play an important role in maintaining AS floc structure and function. Therefore, most researchers believed that EPS was the main influence factor of AS flocculation performance.

In the study, all the reactors were controlled at a solid retention time (SRT) of 15 days, and $\mathrm{Al}^{3+}$ was added to AS with different dosage. The mechanism governing the flocculation of activated sludge (AS) was studied.

\section{Materials and Methods}

The activated sludge (AS) used in this study were cultivated in sequencing batch reactors (SBRs), and each of them had a volume of $4 \mathrm{~L}$. The reactors were seeded with activated sludge (approximately $2500 \mathrm{mg} / \mathrm{L}$ ) from Qu Yang WWTP in Shanghai, China. Temperature was maintained at $20 \pm 1{ }^{\circ} \mathrm{C}$. The activated sludge was collected for the experiments on the condition that the fluctuation of these parameters such as the COD, turbidity and SVI in the effluent was less than $20 \%$. All the activated sludge samples were wasted during the last 10 min of the aeration phase, which guaranteed the SRT is $15 \mathrm{~d}$. 
Eight AS samples, each of which had a volume of $100 \mathrm{~mL}$, were collected separately from 8 SBRs, and each of the AS samples was placed in a $250-\mathrm{mL}$ beaker. Then, the 8 AS samples underwent a two-step flocculation process: rapid mixing with a stirrer at a speed of $117 \mathrm{rpm}$ for $5 \mathrm{~min}$, followed by slow mixing at $50 \mathrm{rpm}$ for $5 \mathrm{~min}$; the operational conditions were identical for the 8 beakers. After flocculation, the bulk solution, LB-EPS, TB-EPS, and the pellet were extracted as follow methods.

The stratification structure and extraction protocol for the AS in this study were modified based on previous research [6]. A $25-\mathrm{mL}$ sample of sludge suspension was centrifuged at $4000 \mathrm{~g}$ for $5 \mathrm{~min}$ at $4{ }^{\circ} \mathrm{C}$, and the supernatant that was carefully collected was the bulk solution. A NaCl solution with the same conductivity as the AS sample was prepared and preheated to $70{ }^{\circ} \mathrm{C}$; then, it was used to re-suspend the AS material in the tube at its original volume before the bulk solution was removed. With no delay, the AS suspension was sheared by a vortex mixer for $1 \mathrm{~min}$; then, it was centrifuged at $4000 \mathrm{~g}$ for $10 \mathrm{~min}$ at $4{ }^{\circ} \mathrm{C}$, and the supernatant was collected as LB-EPS. The AS sample left in the tube was resuspended again to its original volume of $25 \mathrm{~mL}$ with the $\mathrm{NaCl}$ solution and then put in a water bath at $60{ }^{\circ} \mathrm{C}$ for $30 \mathrm{~min}$. It was centrifuged again at $4000 \mathrm{~g}$ for $15 \mathrm{~min}$ at $4{ }^{\circ} \mathrm{C}$ and the supernatant collected was TB-EPS, and the AS sample left was the pellet.

\section{Results and discussion}

The influences of aluminum on the flocculation-related characteristics of AS. The influence of aluminum on the flocculation-related characteristics of AS are listed in Table 1. The effluent turbidity clearly declined as the $\mathrm{Al}^{3+}$ dosage increased. However, when the dosage of $\mathrm{Al}^{3+}$ continuously increased, the decrease rate declined. When the $\mathrm{Al}^{3+}$ dosage was $2 \mathrm{meq} / \mathrm{L}$, the effluent turbidity reached a minimum $(2.72 \pm 0.23 \mathrm{NTU})$. Then the dosage of $\mathrm{Al}^{3+}$ reached $4 \mathrm{meq} / \mathrm{L}$, the effluent turbidity increased (3.69 $\pm 0.13 \mathrm{NTU})$. This indicates that $\mathrm{Al}^{3+}$ dosing can improve activated sludge flocculation effectively, however, over added lead to the decline of flocculation.

Table 1-The influence of aluminum on the flocculation-related characteristics of AS

\begin{tabular}{ccccccccc}
\hline & \multicolumn{7}{c}{ Concentration of aluminum(meq/l) } \\
\cline { 2 - 8 } & 0 & 0.0625 & 0.125 & 0.25 & 0.5 & 1 & 2 & 4 \\
\hline $\begin{array}{c}\text { Mean floc size } \\
{[\mathrm{D}(1,0)](\mathrm{lm})}\end{array}$ & $78.8 \pm 9.4$ & $82.8 \pm 5.6$ & $80.1 \pm 2.1$ & $80.6 \pm 3.4$ & $80.7 \pm 5.3$ & $89.6 \pm 7.3$ & $107.5 \pm 3.2$ & $130.5 \pm 2.5$ \\
$\begin{array}{c}\text { Supernatant } \\
\text { turbidity (NTU) }\end{array}$ & $9.77 \pm 0.54$ & $5.52 \pm 0.23$ & $4.41 \pm 0.68$ & $4.14 \pm 0.23$ & $3.83 \pm 0.12$ & $3.61 \pm 0.22$ & $2.72 \pm 0.23$ & $3.69 \pm 0.13$ \\
& & & & & & & & \\
SVI (mL/g) & $76.6 \pm 4.5$ & $79.9 \pm 2.4$ & $83.6 \pm 3.5$ & $84.1 \pm 6.4$ & $84.3 \pm 2.3$ & $91.9 \pm 8.3$ & $111.1 \pm 1.3$ & $95.8 \pm 9.2$ \\
\hline
\end{tabular}

When the $\mathrm{Al}^{3+}$ dosage was lower $(0.25$ and $0.5 \mathrm{meq} / \mathrm{L})$, the increase of SVI was slight (only $10 \%$ increased). Moreover, as the dosage of $\mathrm{Al}^{3+}$ increased, the SVI was with with a sharp increase. When the $\mathrm{Al}^{3+}$ dosage was $4 \mathrm{meq} / \mathrm{L}$, the SVI was significantly lower than the dosage was $2 \mathrm{meq} / \mathrm{L}$, which was only $25 \%$ increased than no $\mathrm{Al}^{3+}$ added. Though the lower dosage of $\mathrm{Al}^{3+}$ has little influence on sludge sedimentation, the $\mathrm{Al}^{3+}$ dosage can deteriorate the sludge sedimentation.

The influence of total interaction energy on AS flocculation. The total interaction energy curves of AS with different dosage of $\mathrm{Al}^{3+}$ was shown in Fig.1. Without the dosage of $\mathrm{Al}^{3+}$, the was the highest $(696 \mathrm{KT})$. As the $\mathrm{Al}^{3+}$ dosage increased, the total interaction energy declined. When the $\mathrm{Al}^{3+}$ dosage exceeded $0.5 \mathrm{meq} / \mathrm{L}$, the total interaction energy became negative, which has the similar trend with the effluent turbidity. This finding indicates that when the $\mathrm{Al}^{3+}$ dosage was lower than 2 meq/L, the decrease of the total interaction energy can improve activated sludge flocculation. However, when the dosage increased to $4 \mathrm{meq} / \mathrm{L}$, the decrease of the total interaction energy could not improve activated sludge flocculation (Table 1). 


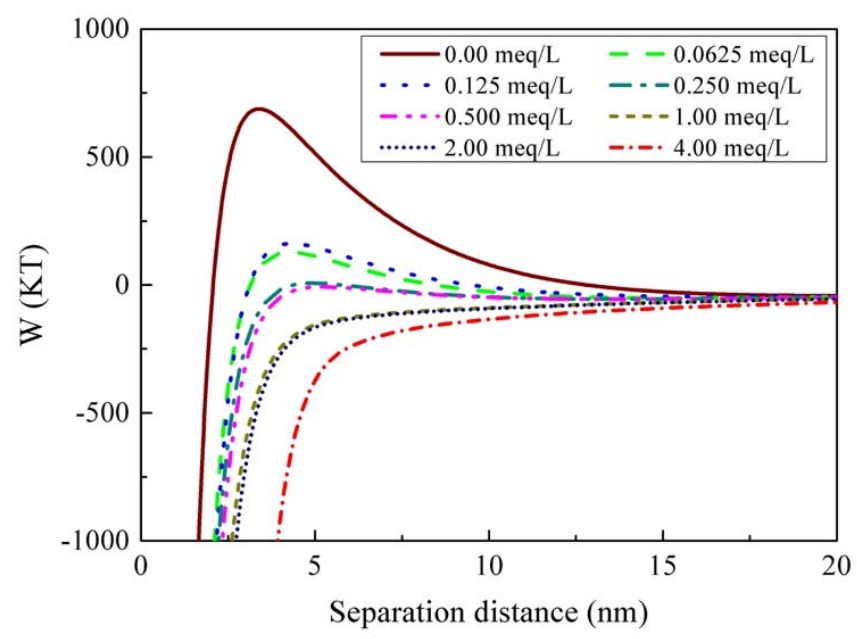

Fig. 1. The total interaction energy curves of AS with different concentrations of aluminum as additives.

The influence of LB-EPS content on AS flocculation. The influences of aluminum on the TOC contents in different parts of the AS was shown in Fig.2. The LB-EPS was declined with the dosage of $\mathrm{Al}^{3+}$ increased, which was the same as TB-EPS. When the $\mathrm{Al}^{3+}$ dosage was extremely low $(0.0625$ meq/L), the LB-EPS has an obviously declined ( $9 \%$ reduction). When the $\mathrm{Al}^{3+}$ dosage was 2 meq/L, the reduction of LB-EPS and TB-EPS was $36 \%$ and $8.4 \%$, respectively. When the $\mathrm{Al}^{3+}$ dosage reached $4 \mathrm{meq} / \mathrm{L}$, the reduction of LB-EPS was $59 \%$ and the TB-EPS was $42 \%$, which was much higher than other dosage of $\mathrm{Al}^{3+}$. With the $\mathrm{Al}^{3+}$ dosage, the reduction in LB-EPS was obviously higher than that in TB-EPS, which was opposite with the effluent turbidity. This suggests that when the dosage of $\mathrm{Al}^{3+}$ was not over added, the reduction of LB-EPS can improve the sludge flocculation.

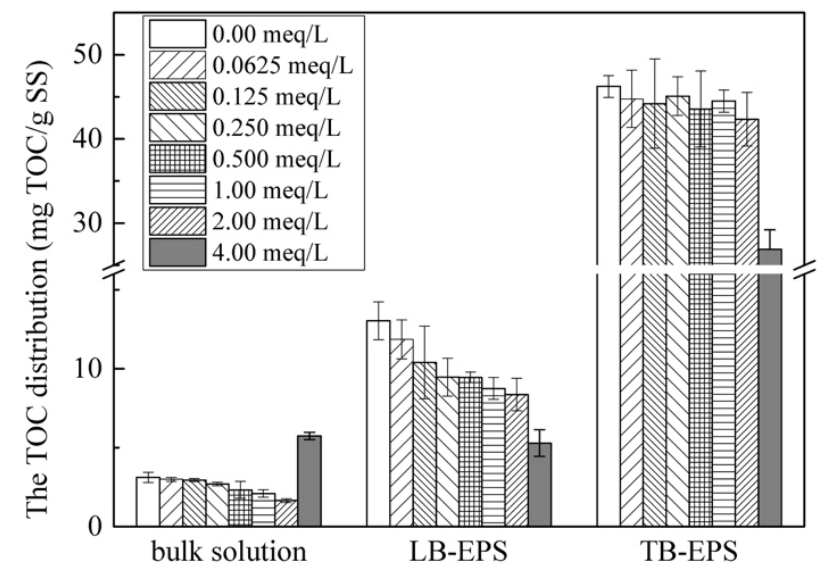

Fig. 2. The influences of aluminum on the TOC contents in different parts of the AS.

\section{Conclusions}

The present study examined the effects of $\mathrm{Al}^{3+}$ dosage on sludge flocculation and sedimentation. The main conclusions are outlined as follows:

i) Activated sludge flocculation and turbidity removal improved with the increasing $\mathrm{Al}^{3+}$ dosage, but sludge sedimentation deteriorated. The SVI values increased sharply as the dosage increased from $1 \mathrm{meq} / \mathrm{L}$ to $2 \mathrm{meq} / \mathrm{L}$. 
ii) The EPS content and interaction energy of AS reduced in gradient as the dosage of $\mathrm{Al}^{3+}$ increased, which suggested that $\mathrm{Al}^{3+}$ could improve AS flocculation.

\section{Acknowledgements}

This work was supported by the Major Science and Technology Program for Water Pollution Control and Treatment of China (2011ZX07318-001) and the National Science Foundation of China (51078284).

\section{References}

[1] T. P. Nguyen, N. Hilal, N. P. Hankins, J. T. Novak: Desalination. Vol. 222 (2008), p. 307-317.

[2] B. M. Wilén, J. L. Nielsen, K. Keiding, P. H. Nielsen: Colloid. Surf. B. Vol. 18 (2000), p. $145-156$.

[3] D. C. Sobeck, M. J. Higgins: Water Res. Vol. 36 (2002), p. 527-538.

[4] G. P. Sheng, H. Q. Yu: Biotechnol. Adv. Vol. 28 (2010), p. 882-894.

[5] B. Frolund, R. Palmgren, K. Keiding, P. H. Nielsen: Water Res. Vol. 30 (1996), p. 1749-1758.

[6] G. H. Yu, P. J. He, L. M. Shao, P. P. He: Environmental Science \& Technology. Vol. 42 (1996), p. 7944-7949. 